\title{
Storage and handling of pretreated lignocellulose affects the redox chemistry during subsequent enzymatic saccharification
}

\author{
Ausra Peciulyte ${ }^{1}$, Nikolaos Xafenias ${ }^{1}$, Mats Galbe ${ }^{2}$, Brian R. Scott ${ }^{3}$, Lisbeth Olsson ${ }^{1}$ and Katja S. Johansen ${ }^{1,4^{*}}$ (i)
}

\begin{abstract}
The decomposition of lignocellulose in nature, as well as when used as feedstock in industrial settings, takes place in a dynamic system of biotic and abiotic reactions. In the present study, the impact of abiotic reactions during the storage of pretreated lignocellulose on the efficiency of subsequent saccharification was investigated. Abiotic decarboxylation was higher in steam-pretreated wheat straw (SWS, up till 1.5\% $\mathrm{CO}_{2}$ ) than in dilute-acid-catalysed steampretreated forestry residue (SFR, up till 3.2\% $\mathrm{CO}_{2}$ ) which could be due to higher iron content in SFR and there was no significant $\mathrm{CO}_{2}$ production in warm-water-washed slurries. Unwashed slurries rapidly consumed $\mathrm{O}_{2}$ during incubation at $50^{\circ} \mathrm{C}$; the behaviour was more dependent on storage conditions in case of SWS than SFR slurries. There was a pH drop in the slurries which did not correlate with acetic acid release. Storage of SWS under aerobic conditions led to oxidation of the substrate and reduced the extent of enzymatic saccharification by Cellic ${ }^{\circledR}$ CTec3. Catalase had no effect on the fractional conversion of the aerobically stored substrate, suggesting that the lower fractional conversion was due to reduced activity of the lytic polysaccharide monooxygenase component during saccharification. The fractional conversion of SFR was low in all cases, and cellulose hydrolysis ceased before the first sampling point. This was possibly due to excessive pretreatment of the forest residues. The conditions at which pretreated lignocellulose are stored after pretreatment significantly influenced the extent and kind of abiotic reactions that take place during storage. This in turn influenced the efficiency of subsequent saccharification. Pretreated substrates for laboratory testing must, therefore, be stored in a manner that minimizes abiotic oxidation to ensure that the properties of the substrate resemble those in an industrial setting, where pretreated lignocellulose is fed almost directly into the saccharification vessel.
\end{abstract}

Keywords: Biotic, Abiotic, LPMO, Catalase, Decarboxylation, $\mathrm{O}_{2}$ consumption

\section{Introduction}

The bioconversion of lignocellulosic feedstocks to ethanol is being commercialised, but further process development is required to improve the economic feasibility. The industrial saccharification of lignocellulose relies on highly optimized commercial enzyme cocktails. Lytic polysaccharide monooxygenases (LPMOs), a group

\footnotetext{
*Correspondence: ksj@ign.ku.dk

1 Division of Industrial Biotechnology, Department of Biology

and Biological Engineering, Chalmers University of Technology, 412

96 Göteborg, Sweden

Full list of author information is available at the end of the article
}

of redox-active enzymes discovered in recent years (Johansen 2016), are important drivers of lignocellulose decomposition. LPMOs are mono-nuclear copper enzymes that require $\mathrm{O}_{2}$ and a source of electrons to cleave glycosidic bonds (Quinlan et al. 2011; Vaaje-Kolstad et al. 2010). They are classified into several auxiliary activity (AA) enzyme families in the CAZy database. Importantly, certain AA9 LPMOs initiate cellulose saccharification by cleaving internal $\beta$-1,4-glycosidic bonds without the need for prior hydration (decrystallisation) of individual cellulose chains. In doing so, LPMOs create access points for processive exo-cellulases (Eibinger 
et al. 2017). Therefore, to achieve efficient saccharification, it is important that $\mathrm{O}_{2}$ and appropriate reductants are present (Müller et al. 2015; Scott et al. 2016). Reductants are inherently present in lignocellulosic materials and may be produced enzymatically. Activated $\mathrm{O}_{2}$ in the form of hydrogen peroxide $\left(\mathrm{H}_{2} \mathrm{O}_{2}\right)$ is an alternative cosubstrate. The understanding of the catalytic mechanism of this enzyme class and the interaction with other redox processes associated with the saccharification of lignocellulose is still incomplete. Catalase can decrease the inactivation of the cellulolytic enzyme cocktail, which is highly dependent on the $\mathrm{O}_{2}$ content and LPMO activity (Scott et al. 2016).

The first process step in biotechnology-based lignocellulosic biofuel production involves pretreatment of the biomass. Pretreated lignocellulosic materials used in laboratory experiments are often stored for extended periods under poorly controlled conditions, where temperature and exposure to air may vary. This is in contrast to the industrial process were the pretreated biomass is typically fed directly into the saccharification reactor.

Abiotic redox processes similar to those that occur in natural water-logged environments affect the saccharification of pretreated lignocellulose. The fact that these processes change the pretreated material is clear from the temperature dependent consumption of $\mathrm{O}_{2}$ and the production of $\mathrm{CO}_{2}$ by the material (Peciulyte et al. 2018).

In the present study, we investigated how storage of steam-pretreated wheat straw (SWS) and dilute-acidcatalysed steam-pretreated forestry residue (SFR) under different conditions influences subsequent enzymemediated saccharification. The underlying hypothesis was that the type and extent of abiotic reactions taking place would depend on the storage conditions, and that they would determine how easily the material could be saccharified. Abiotic reactions were assessed by measuring the degree of oxidation of slurries during storage, the consumption of $\mathrm{O}_{2}$ and release of $\mathrm{CO}_{2}$ during incubation at $50{ }^{\circ} \mathrm{C}$, and the extent of acidifying reactions measured as the change in $\mathrm{pH}$. Materials stored under nitrogen pressure represented non-oxidized substrate, while storage under aerobic conditions at room temperature or $4{ }^{\circ} \mathrm{C}$ represented ageing conditions (Fig. 1).

\section{Materials and methods}

\section{Production and storage of slurries}

SWS was prepared at the Department of Chemical Engineering, Lund University, Sweden. Pretreatment was performed in a bench-scale steam pretreatment unit using saturated steam at $190{ }^{\circ} \mathrm{C}$ for $10 \mathrm{~min}$, without the addition of a catalyst (Bondesson et al. 2013). Spruce tips, branches and needles were harvested, crushed to an average size of $15 \mathrm{~mm}$ and steam pretreated at $209^{\circ} \mathrm{C}$ for $13.5 \mathrm{~min}$, with an acid catalyst loading of $1 \mathrm{~kg}_{4 \% \mathrm{H} 2 \mathrm{SO} 4} /$ $\mathrm{kg}_{\text {DryWeight }}$ in a $30 \mathrm{~L}$ pretreatment reactor at RISE Processum (Örnsköldsvik, Sweden) (SWR). The chemical composition of the slurries is given in the Additional file 1 : Table S1.

Virginiamycin S1 (3 $\mu \mathrm{g} / \mathrm{g}$ slurry, V4140-5MG, Sigma) and Virginiamycin M1 (6 $\mu \mathrm{g} / \mathrm{g}$ slurry, V2753-10MG, Sigma) were added to prevent microbial contamination during the long-term storage.

One portion of SWS and SFR slurries were stored in glass bottles (approx. 1:1, slurry:headspace (wt/vol)) at room temperature exposed to light. The bottles were plugged with butyl rubber stopper and closed with a screw cap with a hole in the middle. The sterile filter $(0.2 \mu \mathrm{m})$ was pierced through the stopper. The bottles were shaken once per week to aerate the slurries. Another portion of SWS and SFR slurries were stored at $4{ }^{\circ} \mathrm{C}$ under $\mathrm{N}_{2}$ pressure (approx. 4 psi) in the darkness, in Oxoid ${ }^{\mathrm{TM}}$ Anaerobic $3.5 \mathrm{~L}$ jars (Thermo Fisher Scientific, Basingstoke, England). Slurries were also stored after pH pre-adjustment to 5.5 for SWS slurry, and to 5.9 for SFR slurry using $1 \mathrm{M} \mathrm{KOH}$. Tap water was used to dilute the slurries. Portions of SWS and SFR were washed with warm water. The supernatants was discarded after centrifugation $\left(5000 \mathrm{~g}\right.$ at $4{ }^{\circ} \mathrm{C}$ for $20 \mathrm{~min}$ ) and approx. $100 \mathrm{~g}$ of the solid fraction was mixed with up to $2 \mathrm{~L}$ tap water. The mixture was heated to $50-60{ }^{\circ} \mathrm{C}$ and stirring continued at this temperature for $30 \mathrm{~min}$. The washing water was then removed by filtration using a $0.2 \mu \mathrm{m}$ polyethersulphone filter (Nalgene Rapid-Flow). The washing procedure was repeated three times. Washed slurries (SWS dry matter (DM) $11 \%$ and SFR DM 24\%) were stored at $4{ }^{\circ} \mathrm{C}$ maximum for two days prior the experiment.

\section{Elemental analysis of lignocellulose}

Both the solid and liquid fractions of water-washed slurries from SWS and SFR were analysed (Additional file 1: Table S1) at the Department of Biology, Lund University, Sweden. Samples were dried at $105{ }^{\circ} \mathrm{C}$. A knife mill (Retsch GmbH, Haan, Germany) was used with a $1 \mathrm{~mm}$ screen during milling. Elemental analysis was carried out using inductively coupled plasma optical emission spectrometry (Optima 8300, Perkin Elmer, Waltham, MA, USA). The solid material $(\sim 0.5 \mathrm{~g})$ was digested in $7 \mathrm{~mL}$ $\mathrm{HNO}_{3}$ and $3 \mathrm{~mL}$ water in a Mars5 microwave (CEM, Matthews, NC, USA) and diluted to $50 \mathrm{~mL}$ with tap water prior to analysis. $\mathrm{C}$ and $\mathrm{N}$ were measured using a Vario MAX CN from Elementar (Langenselbold, Germany) and the ions were analysed with an 861 Advanced Compact IC from Metrohm (Herisau, Switzerland). 


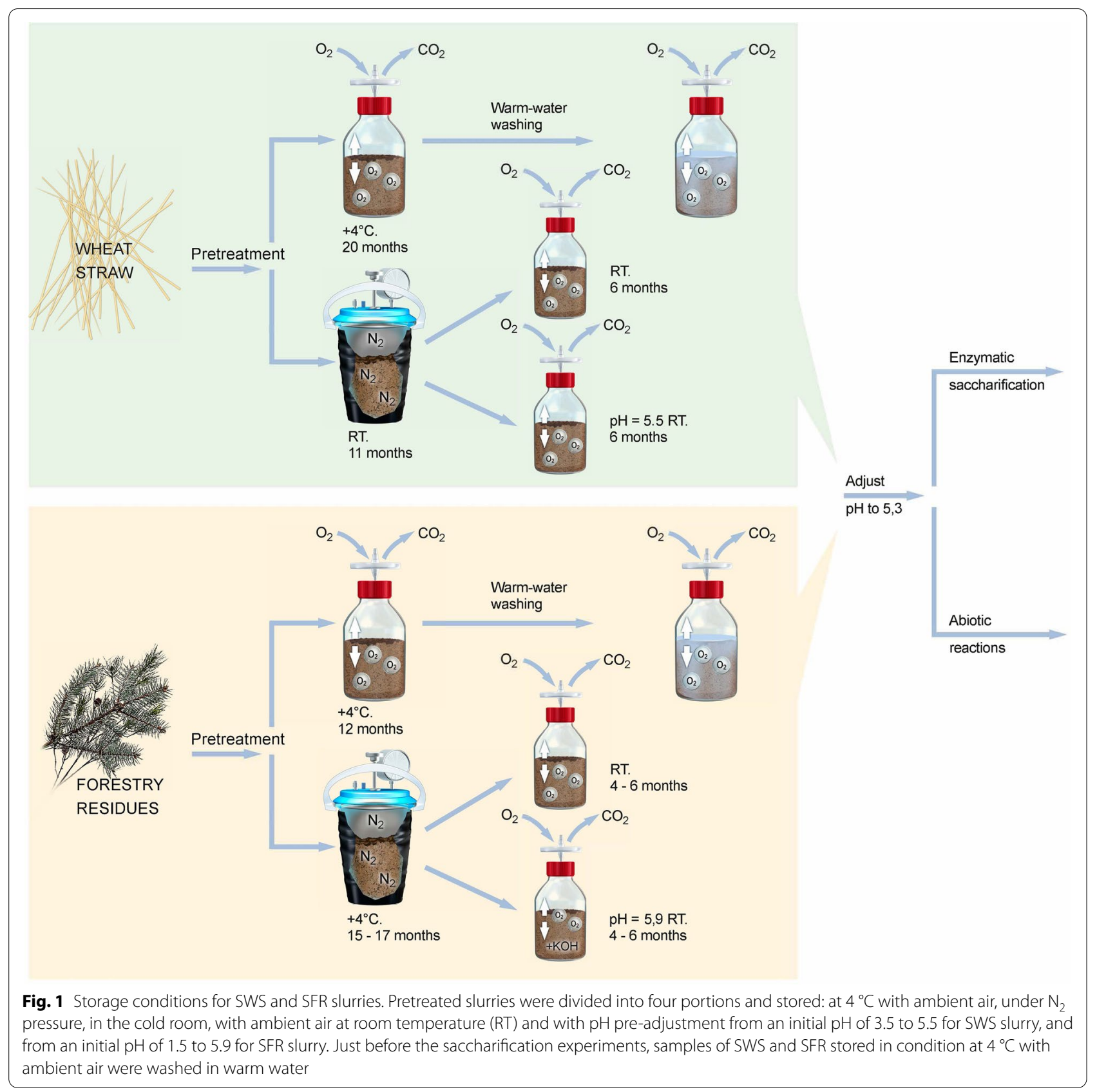

\section{Lignocellulose incubation with and without enzymes}

The enzyme cocktail, Cellic ${ }^{\circledR} \mathrm{CTec} 3$, and catalase from Thermoascus aurantiacus (Accession DD046677) were kindly provided by Novozymes A/S. The catalase preparation was more than $90 \%$ pure. Enzyme stock samples were prediluted with tap water prior to addition to the slurry samples.

During the saccharification of the slurries, CTec3 enzyme loading was $4.7 \mathrm{mg} / \mathrm{g}$ cellulose in unwashed SWS slurry, $4.7 \mathrm{mg} / \mathrm{g}$ cellulose in washed SWS slurry,
$12.2 \mathrm{mg} / \mathrm{g}$ cellulose in unwashed SFR slurry and $12.9 \mathrm{mg} / \mathrm{g}$ cellulose in washed SFR slurry. The catalase loading was $0.25 \mathrm{mg} / \mathrm{g}$ cellulose in unwashed SWS slurry, $0.26 \mathrm{mg} / \mathrm{g}$ cellulose in washed SWS slurry, $0.66 \mathrm{mg} / \mathrm{g}$ cellulose in unwashed SFR slurry and $0.70 \mathrm{mg} / \mathrm{g}$ cellulose in washed SFR slurry. The saccharifications were performed in $50 \mathrm{~mL}$ Falcon tubes on $20 \mathrm{~g} 10 \%$ DM slurry at $50^{\circ} \mathrm{C}$ in ambient air conditions.

Experiments to determine $\mathrm{CO}_{2}, \mathrm{O}_{2}$ saturation and pressure were performed using $15 \mathrm{~g}$ slurry diluted to 2,5 
or $10 \% \mathrm{DM}$ in $30 \mathrm{~mL}$ serum bottles capped with airtight butyl rubber caps (Rubber BV), and sealed with aluminium crimp caps (with a removable centre) prior to incubation. Mixing was performed on an orbital shaker at $180 \mathrm{rpm}$. The $\mathrm{pH}$ was initially adjusted to 5.3 with $\mathrm{KOH}$.

\section{Analysis of $\mathrm{CO}_{2}$ in the headspace}

These experiments were performed as described previously (Peciulyte et al. 2018) using a two-channel gas chromatography GC instrument (490 Micro GC, Agilent Technologies Sweden $A B)$, equipped with a thermal conductivity detector. Channel 1 was equipped with a $10 \mathrm{~m}$-long Molsieve 5 column (Agilent Technologies Sweden $\mathrm{AB}$ ), and helium was used as the carrier gas (at a pressure of $5.44 \mathrm{~atm}$ ), and this was used for the analysis of $\mathrm{N}_{2}$ and $\mathrm{O}_{2}$. Channel 2 was equipped with a $10 \mathrm{~m}$-long CP-PoraPLOT U column (Agilent Technologies Sweden $\mathrm{AB}$ ), argon was used as the carrier gas (at $5.44 \mathrm{~atm}$ ), and this was used for the analysis of $\mathrm{CO}_{2}$. The columns described above also allowed the detection of permanent gases such as methane, $\mathrm{CO}, \mathrm{NO}$, hydrocarbons $\mathrm{C} 1-\mathrm{C} 6$, $\mathrm{H}_{2} \mathrm{~S}, \mathrm{SO}_{2}$, etc.

\section{Pressure measurements}

The pressure in the headspace was measured using a digital manometer (GMH 3111) and a relative pressure sensor (MSD 2,5 BRE; Greisinger Electronic, Regenstauf, Germany). Pressure measurements were performed after incubation of the slurries by inserting a needle connected to the manometer through the septum of the butyl rubber cap of the serum bottles.

\section{$\mathrm{O}_{2}$ content in the headspace and slurry}

The dissolved oxygen content (DO) in the biomass slurry and the $\mathrm{O}_{2}$ content in the headspace were measured as has been described previously (Peciulyte et al. 2018), with two optode sensors mounted inside the serum bottles. The amount of $\mathrm{O}_{2}$ was determined by fluorescent quantification using a Fibox4 oxygen meter (PreSens Precision Sensing GmbH, Germany).

\section{Cyclic voltammetry}

Cyclic voltammetry (CV) experiments were carried out in a $20 \mathrm{~mL}$ voltammetry cell (VC-2; BASi, USA) containing $15 \mathrm{~mL}$ slurry (SWS or SFR; $\mathrm{pH}$ adjusted to 5.0 using $\mathrm{KOH}$ ) in a three-electrode configuration together with a potentiostat. The working electrodes were $3 \mathrm{~mm}$ $\emptyset$ graphite rods (Alfa Aesar, Sweden) with a working surface area of $7.5 \mathrm{~cm}^{2}$. A Pt wire was used as the counterelectrode, along with a $\mathrm{Ag} / \mathrm{AgCl}$ reference electrode (3 M $\mathrm{NaCl}$; RE-5B, BASi, USA) vs. which the working electrode potentials were controlled $(+210 \mathrm{mV}$ vs. Standard Hydrogen Electrode; all electrode potentials given are vs.
$\mathrm{Ag} / \mathrm{AgCl}$ ). A two-channel potentiostat (MLab; Bank Elektronik-Intelligent Controls $\mathrm{GmbH}$, Germany) was used to control the electrode potential and record the current. CV experiments were performed within a scanning range of -200 to $+680 \mathrm{mV}$ to avoid reactions related to $\mathrm{H}_{2}$ and $\mathrm{O}_{2}$ generation which occur below $-500 \mathrm{mV}$ and above $+720 \mathrm{mV}$, respectively, at $\mathrm{pH}$. The $\mathrm{CV}$ scan rate was $10 \mathrm{mV} / \mathrm{s}$ and each experiment was performed at least three times in duplicate reactors. All experiments were conducted under ambient conditions, at room temperature $\left(21 \pm 1{ }^{\circ} \mathrm{C}\right)$. The slurry was only mixed during $\mathrm{pH}$ adjustment, immediately before $\mathrm{CV}$ analysis.

\section{Determination of glucose, xylose and acetic acid}

The saccharified samples were analysed using HPLC with a Rezex ROA-Organic Acid $\mathrm{H}+(8 \%)$ column with a $3 \mathrm{~mm}$ I.D. maintained at $80{ }^{\circ} \mathrm{C}$ with a Carbo-H4 guard cartridge (both from Phenomenex Inc.) maintained at room temperature. As eluent, $5 \mathrm{mM} \mathrm{H}_{2} \mathrm{SO}_{4}$ was used at a flow rate of $0.8 \mathrm{~mL} / \mathrm{min}$. Analytes were detected with a refractive index detector.

\section{Results}

The experiments were carried out to determine abiotic and biotic reactions in pretreated lignocellulosic streams stored at different conditions (as outlined in Fig. 1).

\section{Biomass pretreatment and composition}

SWS was collected directly from the bench-scale steam pretreatment reactor and a portion of it was stored in an airtight container under nitrogen pressure. SFR was obtained from a pilot-scale steam pretreatment reactor and stored in containers under nitrogen pressure upon arrival. Analysis of the chemical composition of the liquid fractions and the washed solid fractions was carried out (Additional file 1: Table S1). The solid fractions differed markedly in their contents of insoluble glucose (mainly present as cellulose) relative to acid-insoluble lignin. The solid fraction of SWS contained $61 \%$ glucose by weight (unless otherwise stated \% is w/w throughout) and 26\% acid-insoluble lignin, while the solid fraction of SFR contained $23 \%$ glucose and $72 \%$ acid-insoluble lignin. The pretreatment of forestry residue appears to have been of high severity degrading large amounts of the carbohydrates. The liquid fractions differed in their xylose and glucose concentrations. The SWS liquid fraction contained more xylose $(19 \mathrm{~g} / \mathrm{L})$, while the SFR liquid fraction contained more glucose $(19 \mathrm{~g} / \mathrm{L})$. Elemental analysis of the slurries was performed (Additional file 1: Table S2). The SFR contained high amounts of sulphur due to the addition of sulphuric acid during pretreatment. The total iron content was approximately $280 \mathrm{mg} / \mathrm{kg}$ for SWS and $430 \mathrm{mg} / \mathrm{kg}$ for SFR. The liquid fraction from SFR 
also contained a high amount of iron (approximately $100 \mathrm{mg} / \mathrm{L}$ slurry when diluted to $10 \%$ DM content) compared to the liquid fraction from SWS (approximately $3 \mathrm{mg} / \mathrm{L}$ at $10 \% \mathrm{DM}$ content). This difference may be the effect of a higher degree of decomposition of SFR than SWS caused by the addition of acid during pretreatment. Also release of iron from the employed equipment during strong acidic conditions cannot be excluded.

The two pretreated slurries were stored and handled as outlined in Fig. 1. The experiments were performed to assess the impact of oxidative modifications that may take place when pretreatment and bioconversion are separated in time. The abiotic reactivity and the efficiency of the enzymatic saccharification of the slurries were investigated as described below.

\section{The contribution of $\mathrm{CO}_{2}$ to headspace pressure}

The degree of abiotic reactions taking place in differently stored materials was assessed. The content of $\mathrm{CO}_{2}$ in the headspace after incubation at $50{ }^{\circ} \mathrm{C}$ for $24 \mathrm{~h}$ was $1-1.5 \%$ for the SWS slurries and $2-3.2 \%$ for the SFR slurries (Fig. 2a, c), which is significantly higher than the content in air $(0.04 \%)$. The $\mathrm{CO}_{2}$ production normalized to the DM was consistently higher in the $5 \%$ DM samples than in the $10 \%$ DM samples stored under the same conditions (Additional file 1: Figure S1).

The pressure differed between SWS and SFR slurries after $24 \mathrm{~h}$ incubation (Fig. 2b, d). For SWS slurries there was a direct correlation between $\% \mathrm{CO}_{2}$ and the headspace pressure. While for SFR slurries, an inverse correlation was seen between $\% \mathrm{CO}_{2}$ and pressure. Surprisingly, an overpressure developed in the headspace above the warm-water-washed samples without any significant
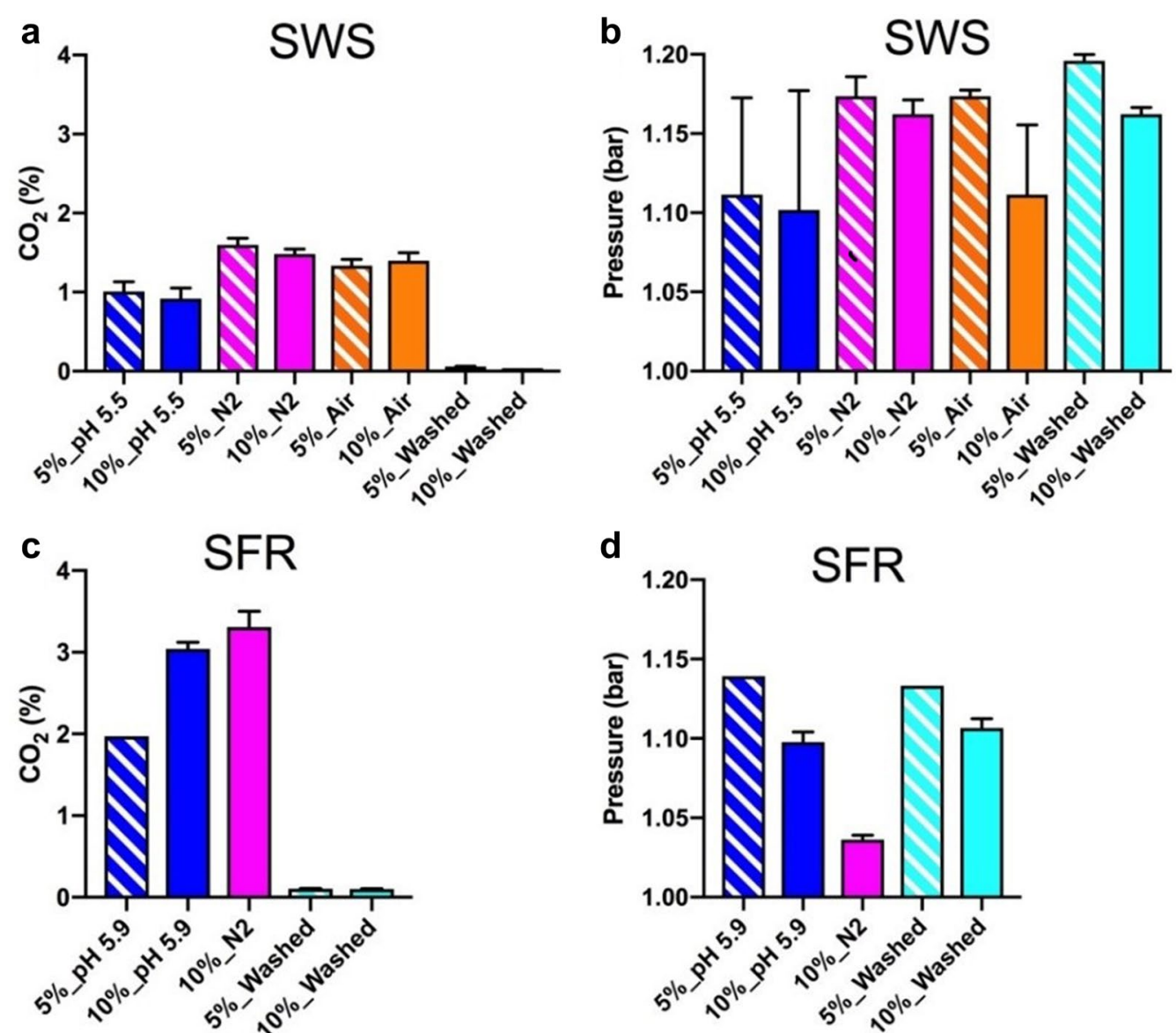

Fig. $2 \mathrm{CO}_{2}$ content $\left(\% \mathrm{CO}_{2}\right)$ and pressure in the headspace of the SWS (a and $\left.\mathbf{b}\right)$ and SFR (c and $\mathbf{d}$ ) slurries after incubation at $50^{\circ} \mathrm{C}$ with shaking at $180 \mathrm{rpm}$ for $24 \mathrm{~h}$. The samples contained $5 \%$ or $10 \%$ dry matter, and the $\mathrm{pH}$ was adjusted to 5.5 (SWS) or pH 5.9 (SFR) prior to storage of the slurries at room temperature under aerobic conditions. $\mathrm{N}_{2}$ denotes storage of the slurries under $\mathrm{N}_{2}$ pressure, and Air storage of the slurries at room temperature exposed to air. Washed denotes warm-water-washed slurries after storage. Each data point is the average value of two to seven replicates (except the 5\%_pH 5.9 measurement which did not have replicates), and error bars show one standard deviation (SD). The right-hand figures show the $\% \mathrm{CO}_{2}$ as a function of pressure for SWS (b) and SFR (d) 
production of $\mathrm{CO}_{2}$. No other volatile analytes that could account for the increased pressure, such as $\mathrm{CO}, \mathrm{NH}_{4}, \mathrm{H}_{2} \mathrm{~S}$ etc. (see methods and materials for details) were detected in the headspace.

\section{$\mathrm{O}_{2}$ consumption was higher in stored and unwashed slurries than in washed slurries}

Rapid consumption of $\mathrm{O}_{2}$, within 30 min of incubation, was observed for the SWS slurries (Fig. 3b), which continued throughout the whole experiment. In 10\% DM SWS slurries almost all the $\mathrm{O}_{2}$ was depleted by the end of the experiment, whereas the DO remained high in the samples containing 5\% DM. The $\mathrm{O}_{2}$ content in the headspace remained high in the serum bottles throughout incubation (Fig. 3a), with only marginal differences between samples containing $5 \%$ or $10 \%$ DM (13-18\% DO).

The $\mathrm{O}_{2}$ was rapidly consumed in the SFR slurries within half an hour of starting incubation (Fig. 3d). The
DO increased after the initial fall, and then continued to decrease. Lower $\mathrm{O}_{2}$ content was found in the headspace of differently stored unwashed slurries containing $10 \%$ DM than in those containing 5\% DM after $24 \mathrm{~h}$ incubation (Fig. 3c). The $\mathrm{O}_{2}$ consumption in the SFR slurries was more dependent on the storage conditions than in the SWS slurries (Fig. 3). The highest $\mathrm{O}_{2}$ consumption in both slurries was seen in those stored under $\mathrm{N}_{2}$ pressure (Fig. 3b, d). Lower $\mathrm{O}_{2}$ consumption was found in warmwater-washed slurries than in unwashed slurries, i.e., the $\mathrm{O}_{2}$ content in $10 \%$ DM washed SWS and SFR slurries was 8 and $12 \%$, respectively, while the $\mathrm{O}_{2}$ content in unwashed slurries was $1 \%$.

\section{Lignocellulose storage conditions affect $\mathrm{pH}$}

For reliable comparison of the $\mathrm{pH}$ values, all samples were allowed to adjust to room temperature prior to measurements. During the long-term storage of slurries with pre-adjusted $\mathrm{pH}$ (condition d in Fig. 1) a reduction
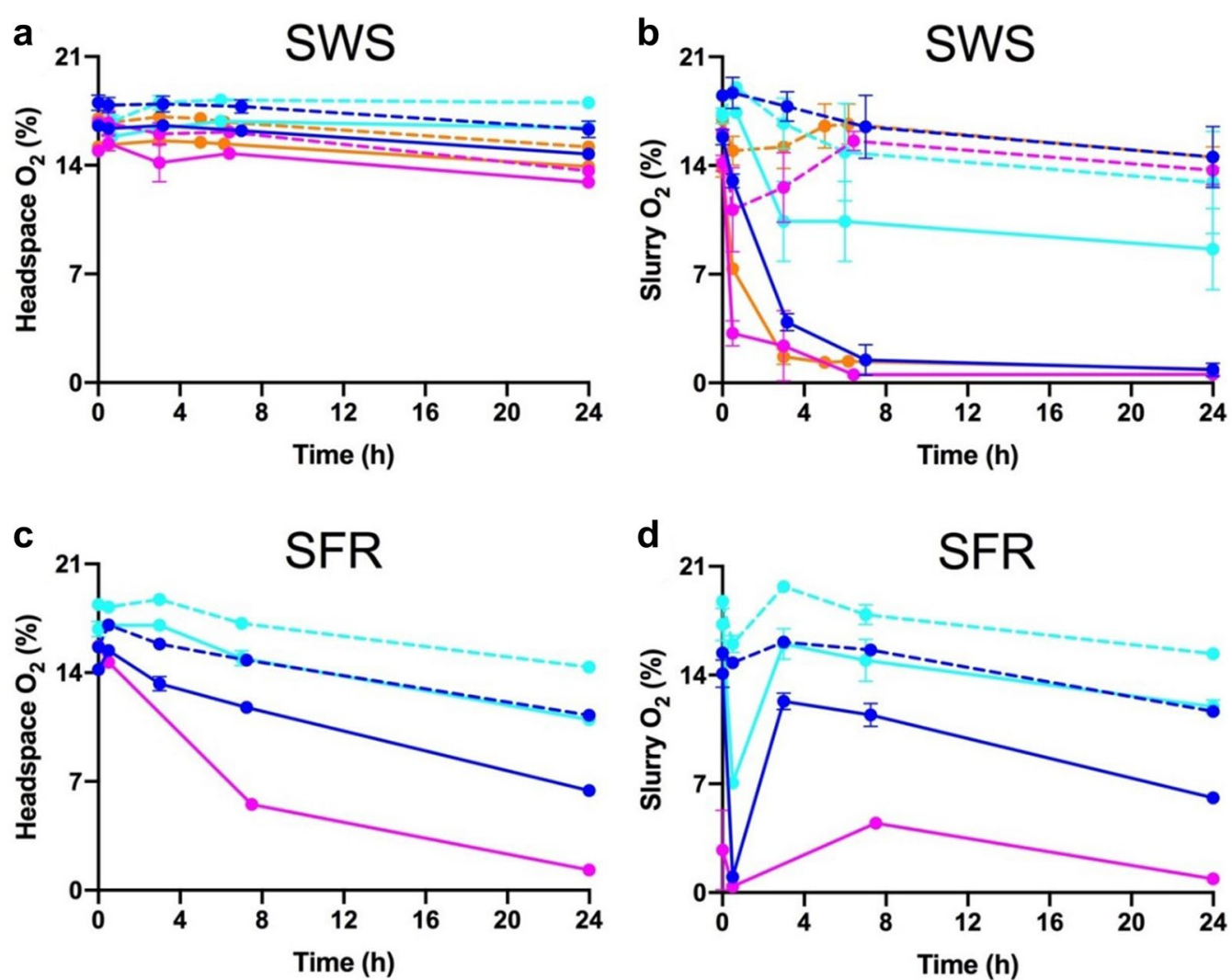

Fig. $3 \mathrm{O}_{2}$ consumption in differently stored wheat straw (SWS) and forestry residue (SFR) slurries during incubation at $50^{\circ} \mathrm{C}$ for $24 \mathrm{~h}$. a, b $\mathrm{O}_{2}$ saturation in SWS headspace and slurry. c, d $\mathrm{O}_{2}$ saturation in SFR headspace and slurry. The pH was adjusted to 5.3 before incubation. Storage conditions of the slurries before incubation: $\mathrm{pH}$ adjusted to 5.5 (SWS) and pH 5.9 (SFR), stored at room temperature under aerobic conditions (blue), and under $\mathrm{N}_{2}$ pressure (magenta), at room temperature under aerobic conditions (orange) and slurries washed with warm water after storage (cyan). Measurements of SFR stored at room temperature under aerobic conditions were not conducted due to the shortage of the material. Dashed line: 5\% DM, continuous line 10\% DM. Each data point is the average value of two to seven replicates (apart from the pH 5.9 SFR measurement which had no replicates), and error bars show 1 SD 
in $\mathrm{pH}$ from 5.5 to 5.0 for SWS slurry and from 5.9 to 5.1 for SFR was observed. No significant changes in $\mathrm{pH}$ were observed in the slurries stored under conditions without $\mathrm{pH}$ adjustment before storage (conditions $\mathrm{a}, \mathrm{b}$, and $\mathrm{c}$ in Fig. 1).

When the slurries after the long-term storage were incubated at $50{ }^{\circ} \mathrm{C}$ while shaking, $\mathrm{pH}$ in SWS slurries fell from 5.3 to $4.9-5.3$ and in SFR to 4.7-4.9 after 4 days (Fig. 4). The pH of the warm-water-washed samples fell to 4.5 (SWS) and 3.6 (SFR), possibly due to the much reduced buffering capacity of these materials than the slurries. No correlation was found between the $\mathrm{pH}$ value during the incubation of the SWS and SFR slurries and acetic acid release (data not shown).

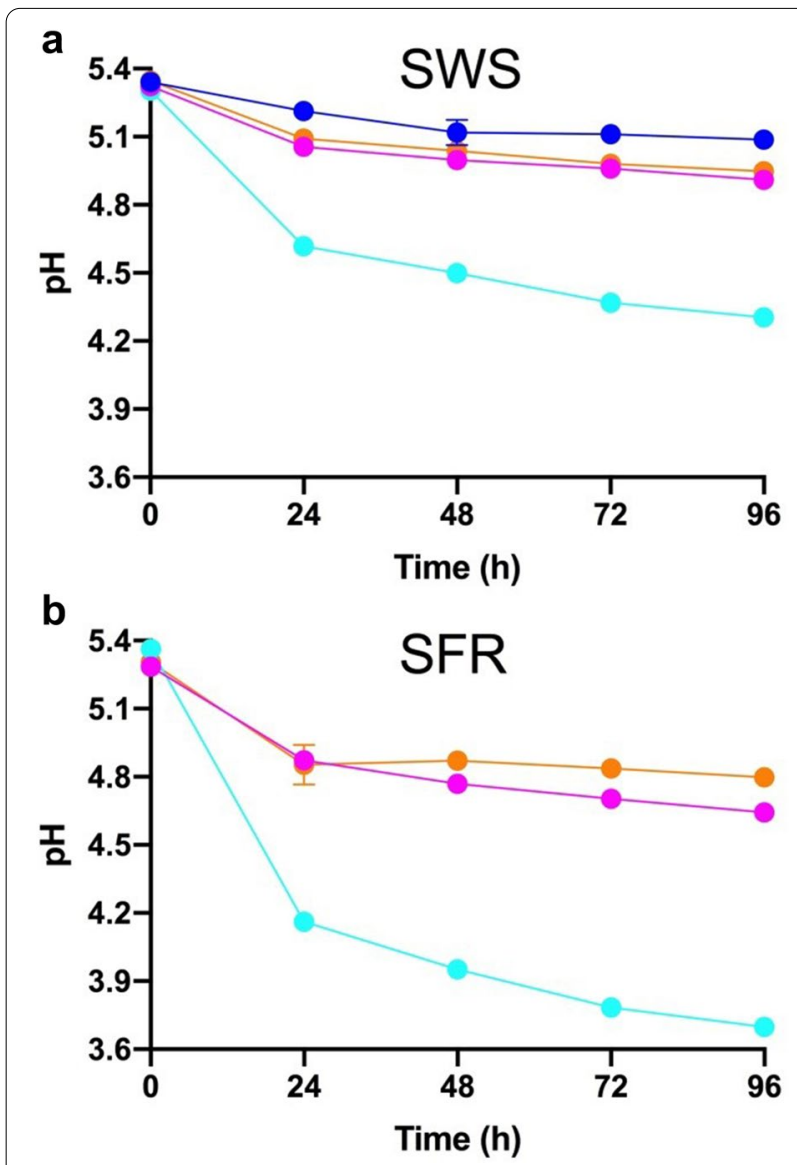

Fig. 4 pH of SWS (a) and SFR (b) slurries as a function of incubation time at $50{ }^{\circ} \mathrm{C}$. After storage, the slurries were diluted to $10 \%$ $\mathrm{DM}$, and the $\mathrm{pH}$ adjusted to 5.3 with $\mathrm{KOH}$. Storage of slurries prior to the experiment: $\mathrm{pH}$ pre-adjusted to 5.5 , stored at room temperature under aerobic conditions (blue), under $\mathrm{N}_{2}$ pressure (magenta), at room temperature under aerobic conditions (orange), warm-water-washed prior to the experiment (cyan). Each data point is the average of two replicates, and error bars show 1 SD
The availability of compounds that can be oxidized is decreased in slurries stored under aerobic conditions

$\mathrm{CV}$ experiments were carried out to evaluate the change in availability of readily-oxidized compounds (potential LPMO reductants) in the liquid fraction of the pretreated materials as a function of storage time. A positive (oxidative) current of similar amplitude was observed before storage, for applied potentials over ca. $+100 \mathrm{mV}$ vs. Ag/ $\mathrm{AgCl}$ in both SWS and SFR slurries (Fig. 5). However, after 14 days of storage, a decrease in oxidative current was observed in both samples, which indicates a decrease in the availability of molecules that can be oxidized by an electrode as electron acceptor without the need for any external catalyst to initiate the reaction. The 10\% DM SWS slurry was further investigated for a period up to 37 days, and a similar trend was observed (Additional file 1: Figure S2).

\section{Large differences in enzymatic conversion of the stored SWS and SFR slurries}

The effect of storage conditions on glucose yield after saccharification of SWS and SFR slurries with Cellic ${ }^{\circledR}$ $\mathrm{CTec} 3$ with and without catalase were performed as has been described previously (Peciulyte et al. 2018).
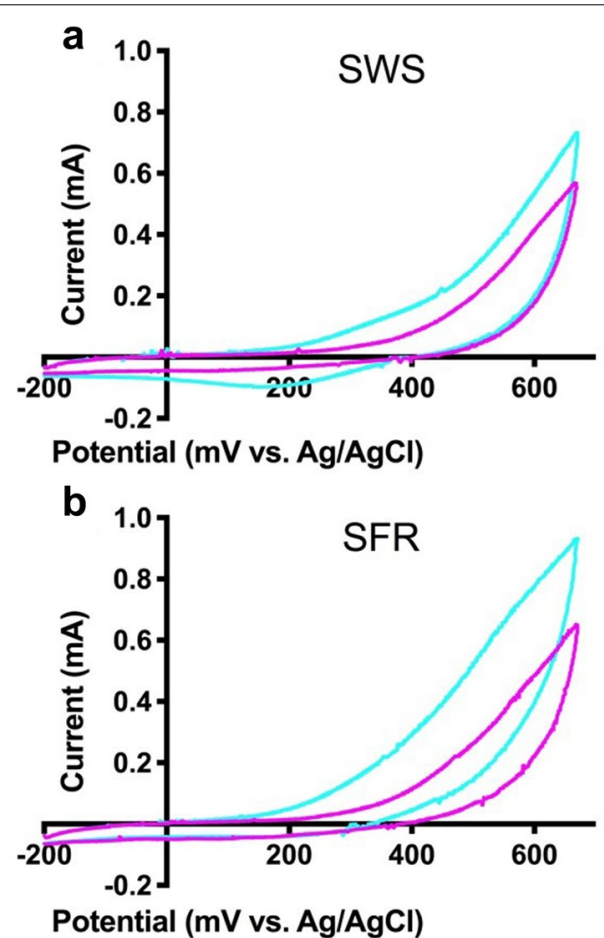

Fig. 5 Cyclic voltammograms obtained from SWS (a) and SFR (b) slurries, showing the effect of storage after 0 (cyan) and 14 days (magenta) under room temperature. Both slurries had 10\% DM. CV was conducted at room temperature and the $\mathrm{pH}$ was adjusted to 5.0 using $\mathrm{KOH}$ 

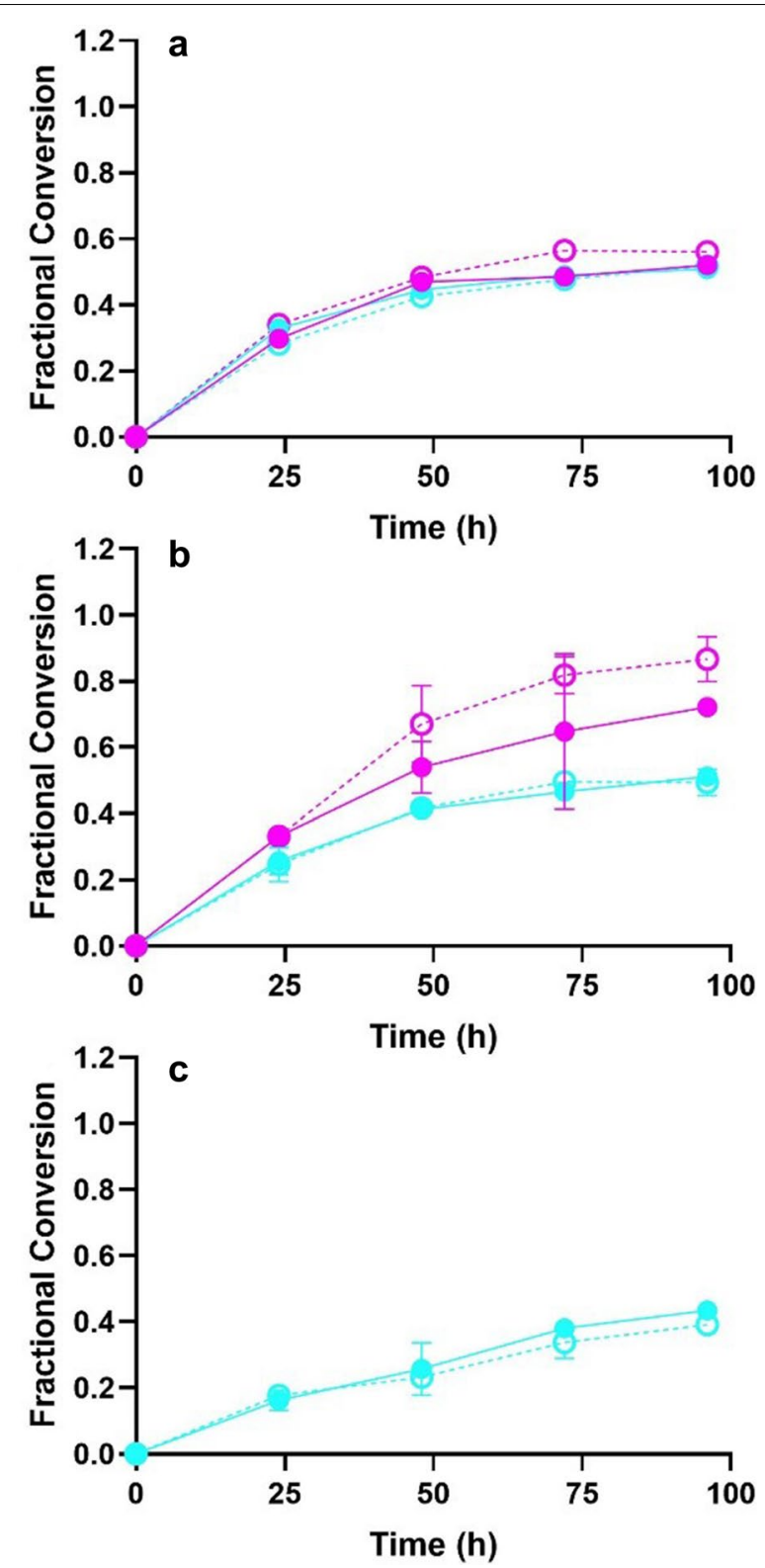

Fig. 6 Effects of different storage conditions on the saccharification of SWS slurry. Slurries were incubated with Cellic ${ }^{\circledR} \mathrm{CTec} 3$ (continuous lines and filled circles) and with Cellic ${ }^{\circledR}$ CTec3 and catalase (dashed lines and open circles). Data are shown from two duplicate experiments (experiment 1: magenta and experiment 2: cyan). Storage conditions of the slurries before the saccharification experiment: room temperature, exposed to air (a), under $\mathrm{N}_{2}$ pressure (b), washed with warm water prior to saccharification (c). Each data point is the average of two replicates, and error bars show 1 SD. In a error bars are shorter than the symbols; therefore, they are not visible

Progress curves for fractional cellulose conversion of pretreated SWS slurry to glucose are shown in Fig. 6. The saccharification progress curve for material stored at $4{ }^{\circ} \mathrm{C}$ and under $\mathrm{N}_{2}$ (magenta Fig. $6 \mathrm{~b}$ ) resembles the curve obtained in our previous study (Peciulyte et al. 2018). After $100 \mathrm{~h}$ of incubation, the fractional conversion was 0.8 without catalase, and 0.9 with catalase. The positive effect on glucose yield of catalase after only $24 \mathrm{~h}$ is also in agreement with our previous work, and it is believed to be due to the lower rate of inactivation of the enzyme cocktail. The pretreated SWS slurry stored at room temperature under aerobic conditions is less amenable to saccharification and the final fractional conversion was below 0.6 (Fig. 6a). The progress curves were almost identical with and without catalase, and in two consecutive experiments, 41 days apart. The same low level of conversion was also seen for the repeat experiment using SWS slurry stored under $\mathrm{N}_{2}$ (Fig. 6b). The container was opened several times to withdraw samples allowing $\mathrm{O}_{2}$ to enter the sample, although the containers were flushed with $\mathrm{N}_{2}$ before closing, we believe that this influenced the aging of the slurry and that it explains the difference in result between the different experiments.

Taken together, these results suggest that SWS slurry is oxidised during storage in the presence of air, resulting in higher recalcitrance. However, storage of the material under nitrogen at $4{ }^{\circ} \mathrm{C}$, or frozen in sealed vacuum bags (Scott et al. 2016) prevented oxidation.

To investigate the effect of soluble compounds in SWS slurry, a portion of the material stored under $\mathrm{N}_{2}$ was thoroughly washed with warm water. The resulting saccharification progress curves show a slow, but steady conversion of the material during the $100 \mathrm{~h}$ of incubation (Fig. 6c). The final level of fractional conversion was approximately 0.5 both with and without catalase.

SFR slurry was stored at ambient temperature in air, or at $4{ }^{\circ} \mathrm{C}$ under $\mathrm{N}_{2}$. These samples were incubated with Cellic ${ }^{\circledR}$ CTec3 as described for SWS slurry above. After $24 \mathrm{~h}$ incubation, the fractional conversion for SFR slurry stored at room temperature in air was 0.3 (Fig. 7a) and for slurry stored cold under $\mathrm{N}_{2}$ pressure 0.2 (Fig. 7b). Hardly any increase in glucose concentration was seen after $24 \mathrm{~h}$. After the stored SFR slurry had been thoroughly washed with warm water to remove all the soluble compounds, the shape of the progress curves was the same as for the unwashed samples, although the resulting degree of conversion was lower, and did not reach 0.2 .

The $\mathrm{pH}$ of SWS and SFR slurries decreased during enzymatic saccharification (Table 1). The addition of catalase had a stabilizing effect on $\mathrm{pH}$ for both SWS and SFR slurries, regardless of the previous storage conditions. In fact, no base titrant was required to maintain the $\mathrm{pH}$ of the SFR slurry samples at $\mathrm{pH} 5$ when catalase was added. The decrease in $\mathrm{pH}$ was greater in samples that were washed with warm water before saccharification, but 

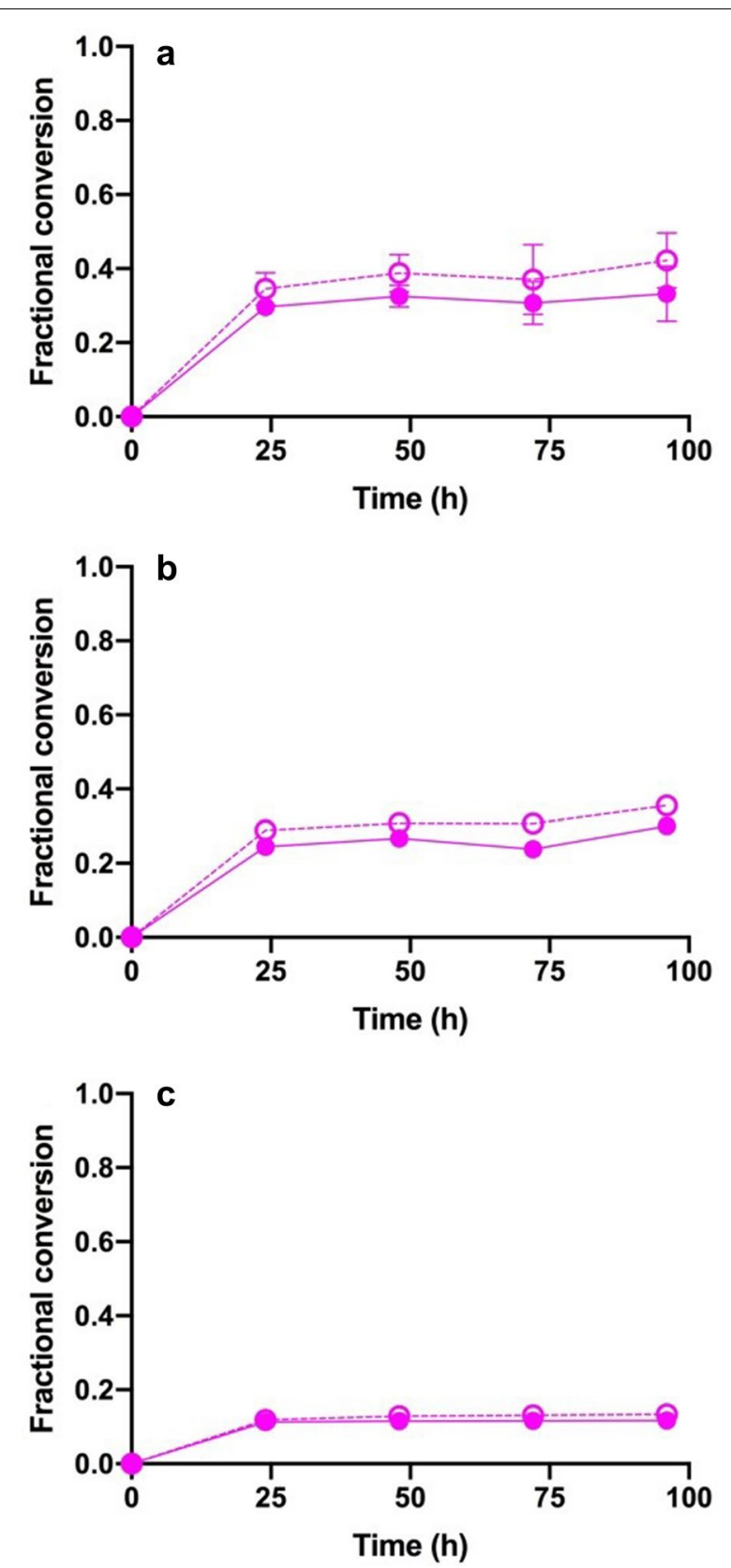

Fig. 7 Effects of different storage conditions on the saccharification of SFR slurry. Slurries were incubated with Cellic ${ }^{\circledR} \mathrm{CTec} 3$ (continuous lines and filled circles) or Cellic ${ }^{\circledR} \mathrm{CTec} 3$ with the addition of catalase (dashed lines and open circles). Storage conditions of slurries prior to saccharification: room temperature in air (a), under $\mathrm{N}_{2}$ pressure $(\mathbf{b})$, washed with warm water prior to saccharification (c). Each data point is the average of two replicates, and error bars show 1 SD

required less titrant than the corresponding saccharification without addition of catalase. This is probably due to the much lower buffering capacity of the suspensions
Table 1 Amount of titrant (1 $\mathrm{M} \mathrm{KOH}$ ) added to adjust the $\mathrm{pH}$ to 5 in samples containing $10 \%$ DM saccharified with Cellic ${ }^{\circledR}$ CTec3 with and without the addition of catalase

\begin{tabular}{|c|c|c|}
\hline Storage and handling & $\begin{array}{l}\text { Titrant addition } \\
(\mathrm{mg}) \text { Cellic }^{\circledR} \text { CTec3 }\end{array}$ & $\begin{array}{l}\text { Titrant addition } \\
\text { (mg) Cellic } \\
\text { CTec3 + Catalase }\end{array}$ \\
\hline \multicolumn{3}{|l|}{ SWS } \\
\hline RT_Air & $324 \pm 50$ & $236 \pm 56$ \\
\hline RT_Air_pH 5.5 & $260 \pm 40$ & $177 \pm 27$ \\
\hline $4{ }^{\circ} \mathrm{C} \_\mathrm{N}_{2}$ & $386 \pm 81$ & $241 \pm 24$ \\
\hline Washed & $117 \pm 18$ & $74 \pm 2$ \\
\hline \multicolumn{3}{|l|}{ SFR } \\
\hline RT_Air & $347 \pm 115$ & 0 \\
\hline $4{ }^{\circ} \mathrm{C} \_\mathrm{N}_{2}$ & $391 \pm 73$ & 0 \\
\hline Washed & $124 \pm 36$ & $55 \pm 3$ \\
\hline
\end{tabular}

Values given are the average of four replicates \pm 1 SD

of washed pretreated material, regardless of the storage conditions.

\section{Discussion}

In a recent study, we showed that oxidative abiotic reactions take place in slurries of steam-pretreated wheat straw during enzymatic saccharification (Peciulyte et al. 2018). $\mathrm{O}_{2}$-consuming reactions led to decarboxylation of steam-pretreated wheat straw and thus acidification of the slurry. This observation raised the question if such reactions could lead to ageing of pretreated materials during storage and handling.

In the present study, ageing of the SWS and SFR slurries during storage was documented by $\mathrm{CV}$. Upon $\mathrm{pH}-$ adjustment to 5.0, a clear oxidative (positive) current was observed on the cyclic voltammograms, demonstrating that the solid-state working electrode could act as an oxidation agent on both materials. An oxidative current was observed without the addition of external catalysts to facilitate the electrochemical reaction, at electrode potentials higher than $100-200 \mathrm{mV}$ vs. $\mathrm{Ag} / \mathrm{AgCl}$. A clear reduction in oxidative current was observed for samples of SWS and SFR stored without any mixing, implying that aging of the samples took place at relatively low DO.

Abiotic $\mathrm{CO}_{2}$ production from organic matter is a nonreversible reaction. The release of $\mathrm{CO}_{2}$ will thus drive the up-stream chemical reactions towards completion. Furthermore, the chemical bonds that are susceptible to decarboxylation under the mild conditions used in this study are limited in number. This was demonstrated by a $30 \%$ reduction in $\mathrm{CO}_{2}$ produced in SWS slurries when the $\mathrm{pH}$ had been pre-adjusted to 5.5 , and then stored at room temperature. It was also found that thorough 
washing of the pretreated slurries before incubation almost completely eliminated the production of $\mathrm{CO}_{2}$.

A recent investigation of the rate of $\mathrm{O}_{2}$ consumption by particulate organic matter in previously anoxic peat soil, (Walpen et al. 2018b) found that abiotic reactions were the primary routes of $\mathrm{O}_{2}$ consumption, rather than microbial respiration. A role of iron and reactive $\mathrm{O}_{2}$ species in the production of $\mathrm{CO}_{2}$ in active soil waters (Page et al. 2013; Trusiak et al. 2018) and in humid tropical forest soils (Hall and Silver 2013) have also been shown. The higher iron content in SFR slurries may be a contributing factor to the higher $\mathrm{CO}_{2}$ production exhibited in SFR slurries compared to SWS slurries. Furthermore, Walpen et al. has recently reported that the pool of electrondonating moieties in peat dissolved organic matter was pH dependent (Walpen et al. 2018a), in agreement with the pH-dependent oxidation of SWS and SFR found in the present study (Additional file 1: S2, S3).

Clear differences were seen in the saccharification progress curves for SWS and SFR slurries. The storage conditions and thereby the extent of oxidation of the pretreated material also influenced the saccharification significantly. Although the SWS used in this study was a new batch of steam-pretreated material, the fractional conversion of the material stored cold under $\mathrm{N}_{2}$ was almost identical to the previously published conversion data (Peciulyte et al. 2018). Saccharification of the warm-water-washed SWS was slow but steady, with no indication of enzyme inactivation or effect of catalase. This is most likely an effect of the removal of soluble LPMO reducing agents. The absence of LPMO activity reduces the efficiency of the hydrolases (Quinlan et al. 2011) and the reduced LPMO activity is a consequence of gradual oxidation of soluble reducing agents during storage as shown by $\mathrm{CV}$.

Low fractional conversion by enzymatic saccharification of SFR could have been anticipated due to the combination of bark (Franko et al. 2015), extractives (Belt et al. 2018) and the addition of the sulphuric acid catalyst (Kellock et al. 2019), all of which may severely reduce the cellulolytic efficiency. The almost complete cessation of saccharification after $24 \mathrm{~h}$ (the first sampling point) for all investigated storage conditions could be the result of either complete enzyme inactivation, inhibition or rapid depletion of accessible substrates.

In the comparable study addressing the effect of storage of pretreated lignocellulose on saccharification efficiency dilute-acid-pretreated corn stover was stored for up to 91 days, and a higher enzymatic saccharification yield was seen after a month of storage (Zhang et al. 2016). Both studies showed that storage resulted in large changes in the hydrolysability after storage, albeit the effects were different.

\section{Conclusions}

Our results demonstrate that abiotic reactions occur in pretreated lignocellulose streams during storage and that the nature and extent of the reactions that take place, depend on the storage conditions and the composition of the lignocellulosic stream. This in turn significantly reduces the efficiency of subsequent enzymatic saccharification of the material. Pretreated substrates for laboratory testing must, therefore, be stored in a manner that minimizes abiotic oxidation to ensure that the properties of the substrate resemble those in an industrial setting, where pretreated lignocellulose is fed almost directly into the saccharification vessel. The complex redox reactions in these settings as well as in natural environments warrant further studies.

\section{Supplementary Information}

The online version contains supplementary material available at https://doi. org/10.1186/s40643-020-00353-3.

Additional file 1. Additional Tables and Figures.

\section{Abbreviations}

SWS: Steam-pretreated wheat straw; SFR: Dilute-acid-catalysed steampretreated forestry residue; LPMO: Lytic polysaccharide monooxygenase; AA: Auxiliary activity; DM: Dry matter; CV: Cyclic voltammetry; DO: Dissolved oxygen content.

\section{Acknowledgements}

We would like to thank Carl Johan Franzén and David Nickel for providing the SFR slurry for this study.

\section{Authors' contributions}

AP and NX performed research, MG prepared SWS slurry, BRS analysed data, $A P, L O$ and KSJ designed research. AP, NX, LO and KSJ wrote the manuscript. All authors commented on the manuscript. All authors read and approved the final manuscript.

\section{Funding}

This work was partially funded by the Swedish Energy Agency, Grant No. 41259-1 to LO and KSJ, and supported by the Novo Nordisk Foundation, Grant NNF17SA0027704 to KSJ.

\section{Availability of data and materials \\ Not applicable.}

Ethics approval and consent to participate

Not applicable.

\section{Consent for publication}

Not applicable.

Competing interests

The authors declare no competing interests.

\section{Author details}

${ }^{1}$ Division of Industrial Biotechnology, Department of Biology and Biological Engineering, Chalmers University of Technology, 41296 Göteborg, Sweden.

${ }^{2}$ Department of Chemical Engineering, Lund University, P.O. Box 124, SE-221 00 Lund, Sweden. ${ }^{3}$ Novozymes Inc, 1445 Drew Ave, Davis, CA 95618, USA.

${ }^{4}$ Department of Geosciences and Natural Resource Management, Copenhagen University, Rolighedsvej 23, 1958 Frederiksberg, Denmark. 
Received: 31 August 2020 Accepted: 2 December 2020

Published online: 12 December 2020

\section{References}

Belt T, Mollerup F, Hanninen T, Rautkari L (2018) Inhibitory effects of Scots pine heartwood extractives on enzymatic holocellulose hydrolysis by wood decaying fungi. Int Biodeterior Biodegradation 132:150-156

Bondesson P-M, Galbe M, Zacchi G (2013) Ethanol and biogas production after steam pretreatment of corn stover with or without the addition of sulphuric acid. Biotechnol Biofuels 6:11

Eibinger M, Sattelkow J, Ganner T, Plank H, Nidetzky B (2017) Single-molecule study of oxidative enzymatic deconstruction of cellulose. Nature Communications 8(1):894

Franko B, Galbe M, Wallberg O (2015) Influence of bark on fuel ethanol production from steam-pretreated spruce. Biotechnol Biofuels 8:15

Hall SJ, Silver WL (2013) Iron oxidation stimulates organic matter decomposition in humid tropical forest soils. Glob Change Biol 19(9):2804-2813

Johansen KS (2016) Discovery and industrial applications of lytic polysaccharide mono-oxygenases. Biochem Soc Trans 44(1):143-149

Kellock M, Maaheimo H, Marjamaa K, Rahikainen J, Zhang H, Holopainen-Mantila U, Ralph J, Tamminen T, Felby C, Kruus K (2019) Effect of hydrothermal pretreatment severity on lignin inhibition in enzymatic hydrolysis. Biores Technol 280:303-312

Müller G, Várnai A, Johansen KS, Eijsink VG, Horn SJ (2015) Harnessing the potential of LPMO-containing cellulase cocktails poses new demands on processing conditions. Biotechnol Biofuels 8:187

Page SE, Kling GW, Sander M, Harrold KH, Logan JR, McNeill K, Cory RM (2013) Dark formation of hydroxyl radical in arctic soil and surface waters. Environ Sci Technol 47(22):12860-12867

Peciulyte A, Samuelsson L, Olsson L, McFarland K, Frickmann J, Østergård L, Halvorsen R, Scott B, Johansen K (2018) Redox processes acidify and decarboxylate steam-pretreated lignocellulosic biomass and are modulated by LPMO and catalase. Biotechnol Biofuels 11(1):165

Quinlan RJ, Sweeney MD, Leggio LL, Otten H, Poulsen J-CN, Johansen KS, Krogh KB, Jørgensen Cl, Tovborg M, Anthonsen A (2011) Insights into the oxidative degradation of cellulose by a copper metalloenzyme that exploits biomass components. Proc Natl Acad Sci 108(37):15079-15084

Scott BR, Huang HZ, Frickman J, Halvorsen R, Johansen KS (2016) Catalase improves saccharification of lignocellulose by reducing lytic polysaccharide monooxygenase-associated enzyme inactivation. Biotech Lett 38(3):425-434

Trusiak A, Treibergs LA, Kling GW, Cory RM (2018) The role of iron and reactive oxygen species in the production of $\mathrm{CO}_{2}$ in arctic soil waters. Geochim Cosmochim Acta 224:80-95

Vaaje-Kolstad G, Westereng B, Horn SJ, Liu Z, Zhai H, Sorlie M, Eijsink VG (2010) An oxidative enzyme boosting the enzymatic conversion of recalcitrant polysaccharides. Science 330(6001):219-222

Walpen N, Getzinger GJ, Schroth MH, Sander M (2018a) Electron-donating phenolic and electron-accepting quinone moieties in peat dissolved organic matter: quantities and redox transformations in the context of peat biogeochemistry. Environ Sci Technol 52(9):5236-5245

Walpen N, Lau MP, Fiskal A, Getzinger GJ, Meyer SA, Nelson TF, Lever MA, Schroth MH, Sander M (2018b) Oxidation of reduced peat particulate organic matter by dissolved oxygen: quantification of apparent rate constants in the field. Environ Sci Technol 52(19):11151-11160

Zhang J, Shao S, Bao J (2016) Long term storage of dilute acid pretreated corn stover feedstock and ethanol fermentability evaluation. Biores Technol 201:355-359

\section{Publisher's Note}

Springer Nature remains neutral with regard to jurisdictional claims in published maps and institutional affiliations.

\section{Submit your manuscript to a SpringerOpen ${ }^{\circ}$ journal and benefit from:}

- Convenient online submission

- Rigorous peer review

- Open access: articles freely available online

- High visibility within the field

- Retaining the copyright to your article

Submit your next manuscript at springeropen.com 